\title{
Elasticidade-renda e concentração das despesas com alimentos no Brasil: uma análise dos dados das POF de 2002-2003, 2008-2009 e 2017-2018*
}

\author{
Income elasticity and concentration of food expenditures in Brazil: an analysis of \\ data from the 2002-2003, 2008-2009 and 2017-2018 Brazilian Family Budget
}

Survey

\author{
Daniela Verzola Vaz e Rodolfo Hoffmann**
}

\begin{abstract}
Resumo: Nas últimas décadas, as despesas com alimentação têm sofrido alterações consideráveis no Brasil, em virtude de mudanças demográficas, econômicas e comportamentais, que afetam as decisões e preferências das famílias sobre o que consumir e onde consumir. A divulgação, no final de 2019, de uma nova edição da Pesquisa de Orçamentos Familiares (POF/IBGE) torna imprescindível a investigação das modificações mais recentes no padrão de dispêndio com alimentos no País. Este artigo tem como objetivo estimar a despesa média mensal familiar e a elasticidade-renda de uma grande variedade de alimentos, comparando-as com os valores obtidos com dados das edições anteriores das POFs. Além disso, são obtidas as razões e curvas de concentração das despesas com alimentos em relação à renda, averiguando-se para quais itens o gasto é mais concentrado nos relativamente ricos do que a própria renda. Os resultados mostram que os gastos médios com alimentação no domicílio continuaram caindo em 2017-2018, ao passo que o gasto com alimentação fora do domicílio interrompeu sua trajetória ascendente, como resultado da crise econômica que atingiu o País a partir de meados de 2014. Houve reversão na tendência de aumento dos gastos com carnes, vísceras e pescados e queda nos gastos com todas as categorias de produtos light/diet. As despesas alimentares mais concentradas em favor dos relativamente ricos estão associadas a uma dieta mais criteriosa e sofisticada.
\end{abstract}

Palavras-chave: Elasticidade-Renda; Curva de Concentração; Despesa com Alimentos; Orçamento Familiar; Brasil

Abstract: Over the last decades, food expenditures have undergone considerable changes in Brazil due to demographic, economic and social changes, which affect household decisions and preferences about what and where to eat. The release, at the end of 2019, of a new edition of the Brazilian Family Budget Survey (POF/IBGE) offers the opportunity to investigate the most recent changes in food expenditure patterns in the

\footnotetext{
* Submissão: 20/12/2019; aprovação: 05/04/2020. DOI: 10.5380/re.v41i75.70940.

** Respectivamente, professora do Departamento de Economia da Universidade Federal de São Paulo (Unifesp). E-mail: daniela.vaz@unifesp.br. ORCID: 0000-0003-4505-6318. Professor Sênior da Escola Superior de Agricultura "Luiz de Queiroz" da Universidade de São Paulo (ESALQ-USP). E-mail: hoffmannr@usp.br. ORCID: 0000-0002-2077-8202. O autor agradece o apoio do CNPq.
} 
country. The objective of this paper is to estimate the average monthly household expenditure and income elasticity of several types of foods and compare them with the corresponding results from previous POFs editions. In addition, concentration curves and ratios in relation to income are also estimated and used in evaluating which types of food are more concentrated in relatively wealthy families than the income itself. Results show that food expenditures at home continued to drop in 2017-2018, while expenditures outside the home interrupted its upward trajectory, as a result of the economic crisis that hit the country from mid-2014. There has also been a reversal in the trend of increasing spending on meat, viscera and fish and a decrease on all categories of light/diet products expenditures. The most concentrated food expenses in the relatively wealthy families are related to a healthier and more sophisticated diet.

Keywords: Income Elasticity; Concentration Curve; Food Expenditure; Family Budget; Brazil

JEL Code: D12 


\section{Introdução}

Os gastos com alimentação vêm perdendo importância no orçamento das famílias brasileiras nas últimas décadas: sua participação na despesa média mensal familiar era de 33,9\% em 1974-1975, tendo declinado para 20,8\% em 2002-2003 e para 17,5\% em 2017-2018 (IBGE, 2019, p. 47). O crescimento da renda per capita e a redução da desigualdade em sua distribuição (entre 2001 e 2014) ajudam a compreender essa alteração no padrão de consumo das famílias e ilustram o comportamento descrito pela Lei de Engel.

Além de perderem participação no orçamento familiar, as despesas com alimentação têm sofrido alterações em virtude de mudanças demográficas, educacionais e comportamentais, que afetam as decisões e preferências das famílias sobre o que consumir e onde consumir. $\mathrm{O}$ aumento da escolaridade média da população, a queda da fecundidade, o aumento da longevidade, os processos de industrialização e urbanização e o ingresso crescente da mulher no mercado de trabalho disseminaram novos costumes e hábitos de consumo. A título de exemplo, pode-se destacar que a participação da alimentação fora do domicílio nas despesas alimentares médias das famílias saltou de 24,1\% em 2002-2003 para 32,8\% em 2017-2018 (IBGE, 2019).

A divulgação, em outubro de 2019, de uma nova edição da Pesquisa de Orçamentos Familiares (POF/IBGE), com dados coletados no período de junho de 2017 a julho de 2018, oferece a possibilidade de investigar as modificações mais recentes no padrão de dispêndio com alimentos no País. Em vista disso, este artigo tem como objetivo estimar os gastos e as elasticidades-renda de diversas categorias de despesas com alimentos, atualizando os cálculos anteriores de Hoffmann (2010, 2007), que haviam se baseado nos dados das POF de 2008-2009 e de 2002-2003. Além disso, avança-se em relação a esses artigos ao se obterem as razões e curvas de concentração das despesas com alimentos em relação à renda, averiguando-se, assim, para quais itens alimentares o gasto é mais (ou menos) concentrado nos relativamente ricos do que a própria renda. Nesse sentido, este trabalho se insere no corpo da literatura que versa sobre bem-estar social. A comparação da distribuição das despesas com a distribuição da renda e a estimação das elasticidades-renda podem trazer à tona elementos que auxiliem na definição e no desenho de políticas públicas que elevem o nível de bem-estar das famílias pobres, 
por meio do aumento do consumo de alimentos ricos em nutrientes e da redução de sua exposição à insegurança alimentar.

A metodologia adotada para o cálculo das elasticidades-renda compreende, preliminarmente, o agrupamento dos indivíduos em dez classes de renda familiar per capita, e, o cálculo, para cada classe, do valor médio da renda per capita e dos vários tipos de despesa com alimentos per capita. Utilizando as médias por classe, ajusta-se uma função poligonal com três segmentos do logaritmo da despesa per capita em função do logaritmo da renda familiar per capita. Esse cálculo é replicado para as despesas com alimentação fora do domicílio, bem como para cada um dos 16 grupamentos de produtos em que é subdividida a despesa com alimentação dentro de casa. Além disso, também são calculadas as elasticidadesrenda de alimentos tradicionais na dieta do brasileiro, como arroz, feijão, macarrão, batata, tomate, banana, laranja, carne, frango, leite, pão francês e café, entre outros. O método para a obtenção das razões e curvas de concentração das despesas com alimentos em relação à renda, por seu turno, guarda estreita analogia com o cálculo do índice de Gini e da curva de Lorenz.

Este artigo está dividido em cinco seções, sendo esta introdução a primeira delas. A seção 2 apresenta uma breve revisão das mudanças observadas no padrão alimentar dos brasileiros desde a década de 70, identificadas principalmente com base em estudos empíricos baseados nas sucessivas ondas da POF. A seção 3 introduz algumas estatísticas descritivas e apresenta a metodologia adotada para o ajuste da função poligonal e para o cálculo das razões e curvas de concentração. A quarta seção apresenta os resultados, comparando-os, sempre que possível, com aqueles obtidos nas edições de 2002-2003 e de 2008-2009 da POF. A última seção apresenta as conclusões do estudo.

\section{Antecedentes}

A aquisição de alimentos tem sofrido alterações importantes no Brasil nas últimas décadas, como consequência das mudanças demográficas, educacionais e comportamentais pelas quais o País passou no período. $\mathrm{O}$ aumento da escolaridade e do nível de vida médio da população, a queda da fecundidade, o aumento da longevidade, os processos de industrialização e urbanização e o ingresso crescente da mulher no mercado de trabalho são exemplos de tais mudanças, tendo sido amplamente discutidas na literatura econômica. Muitas de suas implicações no 
padrão de consumo alimentar dos brasileiros ainda se fazem sentir, merecendo, assim, uma revisão, ainda que breve, neste artigo.

O aumento da parcela dos gastos familiares com alimentação fora de casa tem sido uma das mudanças mais evidentes nos hábitos alimentares da população. Entre suas causas apontam-se a urbanização crescente, o aumento da renda familiar, o aumento da taxa de participação das mulheres no mercado de trabalho, a diminuição do preço de alimentos prontos para consumo e a crescente oferta de serviços voltados para essa finalidade. A esse respeito, merece menção a profusão e variedade de estabelecimentos comerciais destinados à preparação de refeições, que vão desde os tradicionais restaurantes à la carte, até os do tipo self service e "prato feito", passando pelas redes de lanchonetes fast food, bares, padarias, e incluindo os vendedores ambulantes (LEAL, 2010). Segundo dados do Inquérito Nacional de Alimentação da POF 2008-2009, o percentual de indivíduos na população brasileira com 10 anos ou mais de idade que reportam consumir alimentos fora do domicílio é de $40 \%$, sendo que esse valor diminui com a idade, aumenta com a renda per capita e a escolaridade e é maior entre homens, nas áreas urbanas e nas regiões Sudeste, Sul e Centro-Oeste do País (BEZERRA et al., 2013; HOFFMANN, 2013).

Outra faceta da mudança nos hábitos alimentares dos brasileiros é a redução do consumo de gêneros tradicionais, como arroz, feijão, batata, pão e açúcar. O consumo per capita de feijão, por exemplo, tem diminuído no Brasil desde a década de 70 (FGV, 1991; VIEIRA, 1994; MONDINI; MONTEIRO, 1994). Hoffmann (1995) mostra que esse fenômeno esteve associado ao intenso processo de urbanização da população brasileira, tendo em vista que a despesa per capita com feijão nas áreas urbanas corresponde a 70\% do valor observado nas áreas rurais. Apesar disso, arroz e feijão ainda estão entre os alimentos mais frequentes na dieta do brasileiro, independentemente do sexo ou do estrato de renda familiar considerado, de acordo com os dados do Inquérito Nacional de Alimentação da POF 2008-2009 analisados por Souza et al. (2013). O arroz é o alimento mais citado pelos entrevistados (84\%), ao serem indagados sobre os alimentos e bebidas consumidos em dois dias não consecutivos, seguido de café (79\%), feijão (72,8\%), pão de sal (63\%) e carne bovina $(48,7 \%)$.

A diminuição do consumo de alimentos tradicionais tem sido acompanhada pela expansão da aquisição de produtos industrializados, prontos para consumo ou 
de fácil preparo. Souza, Oliveira e Burnquist (2013), por exemplo, verificaram que, entre as POFs 2002-2003 e 2008-2009, ocorreu uma queda importante no consumo per capita de açúcar (de $35 \%$ para o açúcar cristal e de $49 \%$ para o açúcar refinado), acompanhada de aumento no consumo de produtos industrializados que levam açúcar em sua composição - como doces, conservas, balas, iogurtes, sucos e molhos prontos, entre outros. Vale notar que no período analisado pelos autores o aumento da renda real da população e a melhora em sua distribuição permitiram a popularização do consumo de alimentos industrializados - pelos quais havia uma demanda reprimida por parte das classes com menores rendimentos. Fatores como baixa inflação, distribuição de renda por meio de programas sociais focalizados nos mais pobres, reajustes do salário mínimo e marketing eficiente contribuíram para o crescimento de um mercado de consumo popular para os gêneros alimentícios industrializados.

A depender da extensão de seu processamento industrial, os alimentos podem ser classificados em in natura ou minimamente processados, processados e ultraprocessados. Nesse último grupo estão incluídos biscoitos doces e salgados, salgadinhos tipo chips, guloseimas em geral, lanches do tipo fast food, macarrão instantâneo, vários tipos de pratos prontos ou semiprontos e refrigerantes (LOUZADA et al., 2015). A participação dos produtos ultraprocessados no consumo médio diário de calorias dos moradores dos domicílios metropolitanos do País passou de 18,7\% em 1987-1988 para 29,6\% em 2008-2009 (MARTINS et al., 2013). Em nível nacional, estima-se que 21,5\% do consumo médio diário de energia per capita provenham de alimentos ultraprocessados, de acordo com dados da POF 2008-2009 (LOUZADA et al., 2015). Esses alimentos apresentam, em média, características nutricionais desfavoráveis quando comparados aos alimentos in natura ou minimamente processados, como maior densidade energética, maior teor de gorduras, de sódio e de açúcar livre e menor teor de fibras e de proteínas, e seu consumo tem sido associado à maior prevalência de doenças cardiovasculares, diabetes e alguns tipos de câncer.

Cumpre destacar, por fim, o efeito da preocupação com a saúde no padrão de consumo alimentar da população. Nos países desenvolvidos, onde o acesso às informações e o poder aquisitivo são maiores, o risco à saúde decorrente da ingestão de alimentos contaminados por resíduos de produtos químicos tem levado ao aumento do consumo de orgânicos. No Brasil os estudos sobre o consumo per 
capita de alimentos orgânicos baseados em dados provenientes de amostras nacionalmente representativas ainda são escassos, dificultando a comparabilidade intertemporal. As evidências existentes mostram que a probabilidade de consumir esse tipo de alimento aumenta com a renda familiar per capita e com a escolaridade da pessoa de referência da família (OLIVEIRA; HOFFMANN, 2015).

\section{Material e Métodos}

\subsection{Base de dados}

A base de dados utilizada neste trabalho foi a Pesquisa de Orçamentos Familiares (POF), conduzida pelo Instituto Brasileiro de Geografia e Estatística (IBGE). A POF é uma pesquisa domiciliar, de natureza amostral, que tem como finalidade coletar informações sobre gastos e rendimentos das unidades de consumo $^{2}$ dos domicílios particulares permanentes do País.

A POF encontra-se em sua quinta edição ${ }^{3}$, tendo ido a campo nos biênios 1987-1988, 1995-1996, 2002-2003, 2008-2009 e 2017-2018. Na literatura econômica nacional, os estudos microeconômicos sobre os gastos e a demanda do consumidor foram, em grande medida, impulsionados por essas sucessivas ondas de divulgação de dados. Cumpre destacar, porém, que apenas a partir da edição de 2002-2003 a pesquisa adquiriu abrangência nacional. Por esse motivo, neste trabalho apenas as informações relativas às três últimas edições foram comparadas.

Em sua edição mais recente (2017-2018), a amostra da POF continha 58.039 famílias ou "unidades de consumo" e 178.431 pessoas, que, ponderadas pelos fatores de expansão fornecidos com a pesquisa, correspondiam a uma população de 69.017.704 famílias e 207.103.790 indivíduos.

Embora a POF investigue as despesas familiares (monetárias e não monetárias) em categorias como Alimentação, Habitação, Vestuário, Transporte, Higiene e Cuidados Pessoais, Assistência à Saúde, Educação, Recreação e Cultura, Serviços Pessoais, entre outras, apenas os gastos em Alimentação foram objeto de análise neste trabalho.

\footnotetext{
2 A unidade de consumo é definida como o conjunto de moradores que partilham da mesma fonte de alimentação ou compartilham as despesas com moradia. Na maior parte dos casos, a unidade de consumo coincide com o conceito de família adotado pelo IBGE no Censo demográfico. Por esse motivo, esses termos são utilizados de maneira intercambiável neste trabalho.

${ }^{3}$ A POF foi precedida pelo Estudo Nacional de Despesa Familiar (ENDEF/IBGE), com dados coletados nos anos de 1974 e 1975.
} 
As despesas com alimentação 4 são classificadas na POF em "Alimentação no domicílio" e "Alimentação fora do domicílio". Somadas, elas representavam, em 2017-2018, 14,2\% da despesa total e 17,5\% das despesas de consumo realizadas pelas famílias (IBGE, 2019, p. 48). A despesa com alimentação fora do domicílio tem crescido em importância: sua participação na despesa média mensal das famílias com alimentação saltou de 24,1\% em 2002-2003 para 31,1\% em 20082009, tendo chegado a 32,8\% em 2017-2018 (IBGE, 2019).

As despesas com alimentação no domicílio são subdivididas pelo IBGE em 16 grupamentos de produtos, a saber: (1) Cereais, leguminosas e oleaginosas; (2) Farinhas, féculas e massas; (3) Tubérculos e raízes; (4) Açúcares e derivados; (5) Legumes e verduras; (6) Frutas; (7) Carnes, vísceras e pescados; (8) Aves e ovos; (9) Leites e derivados; (10) Panificados; (11) Óleos e gorduras; (12) Bebidas e infusões; (13) Enlatados e conservas; (14) Sal e condimentos; (15) Alimentos preparados; e (16) Outros alimentos.

A Tabela 1 mostra a participação dos principais grupamentos de produtos na despesa média mensal das famílias com alimentação no domicílio, nas três últimas edições da POF. Conforme se vê, a maior parcela das despesas é com Carnes, vísceras e pescados. O grupo cuja participação mais cresceu foi o de "Outros Alimentos", que inclui despesas em varejões, sacolões e feiras, com cestas de produtos (por exemplo, cesta básica e cesta natalina), e, também, despesas em que não é possível individualizar o alimento (agregados). Por outro lado, o grupo que mais perdeu participação foi o de Cereais, leguminosas e oleaginosas, seguido de Óleos e gorduras.

\footnotetext{
${ }^{4}$ Cumpre notar que, quando um produto foi recebido gratuitamente pela família (por exemplo, uma cesta básica que tenha sido doada), o informante foi solicitado a informar os valores dos produtos a preços vigentes no mercado local, que foram registrados como despesa e também como rendimento da unidade de consumo.
} 
Tabela 1 - Distribuição da despesa monetária e não monetária média mensal familiar com alimentação no domicílio, segundo os grupos de produtos, Brasil, 2002/2018

\begin{tabular}{lr|r|r}
\hline \multicolumn{1}{c|}{ Categoria } & POF 2002-2003 & POF 2008-2009 & POF 2017-2018 \\
\hline Cereais, leguminosas e & & & \\
oleaginosas & 10,4 & 8,0 & 5,0 \\
Farinhas, féculas e massas & 5,7 & 4,6 & 3,6 \\
Açúcares e derivados & 5,9 & 4,6 & 4,5 \\
Legumes e verduras & 3,0 & 3,3 & 3,6 \\
Frutas & 4,2 & 4,6 & 5,2 \\
Carnes, vísceras e pescados & 18,3 & 21,9 & 20,2 \\
Aves e ovos & 7,1 & 6,9 & 7,6 \\
Leites e derivados & 11,9 & 11,5 & 10,6 \\
Panificados & 10,9 & 10,4 & 10,3 \\
Óleos e gorduras & 3,4 & 2,3 & 1,7 \\
Bebidas e infusões & 8,5 & 9,7 & 10,6 \\
Alimentos preparados & 2,3 & 2,9 & 3,4 \\
Outros alimentos & 8,3 & 9,4 & 13,7 \\
\hline Total & $\mathbf{1 0 0}$ & $\mathbf{1 0 0}$ & $\mathbf{1 0 0}$ \\
\hline
\end{tabular}

Fonte: IBGE (2019, p. 53).

\subsection{Metodologia}

\subsubsection{Elasticidades-renda}

Neste trabalho, estimaram-se as elasticidades-renda das despesas familiares per capita com alimentação dentro e fora do domicílio. No caso da alimentação no domicílio, as elasticidades foram calculadas para cada um dos grupos de alimentos definidos pelo IBGE, bem como para uma grande variedade de produtos que são frequentes na dieta do brasileiro, como arroz, feijão, macarrão, batata, tomate, banana, laranja, carne, frango, leite, pão francês e café, entre outros.

O método de estimação das elasticidades-renda consiste em ajustar uma função poligonal mostrando como o logaritmo da despesa per capita com um determinado alimento (ou grupo de alimentos) varia em função do logaritmo da renda familiar per capita. Porém, em lugar de se utilizarem dados individuais, são considerados os valores médios de despesa e renda em dez classes da renda familiar per capita (RFPC). Essa estratégia se justifica porque leva a resultados mais coerentes que aqueles que seriam obtidos ao se estimar uma regressão de mínimos quadrados com dados individuais. Isso porque ao se adotarem valores médios por classes da RFPC atenuam-se os erros de medida nessa variável, que 
são típicos de pesquisas de natureza domiciliar. Ao se negligenciar esse problema, as estimativas de mínimos quadrados da elasticidade-renda não são consistentes, tendendo a subestimar o verdadeiro valor absoluto desse parâmetro.

Assim como em Hoffmann (2007, 2010), foram consideradas dez classes da RFPC, conforme mostra a Tabela 2, a seguir. Os limites das classes foram estabelecidos de modo a evitar que uma delas detivesse uma proporção muito elevada da população ou da renda total. Ainda assim, fica evidente o elevado grau de concentração da renda. A primeira classe, que compreende os indivíduos com RFPC inferior a $\mathrm{R} \$ 400$, contém $14,39 \%$ da população, mas apenas 2,05\% da renda total. Em contraste, a última classe, na qual estão os indivíduos cuja RFPC é maior do que $\mathrm{R} \$ 10.000$, inclui apenas $1,78 \%$ das pessoas e $17,41 \%$ da renda. Outro aspecto que merece destaque é o número médio de pessoas por família $(3,00)$, bastante inferior ao observado na POF 2008-2009 (3,30) e na POF 2002-2003 $(3,62)$.

Tabela 2 - Pessoas e famílias por classes da renda familiar per capita, Brasil, 2017-2018

\begin{tabular}{|c|c|c|c|c|c|c|c|}
\hline \multirow{2}{*}{$\begin{array}{c}\text { Classes da renda } \\
\text { familiar per capita } \\
\text { (R\$) }\end{array}$} & \multicolumn{2}{|c|}{ Pessoas } & \multicolumn{2}{|c|}{ Famílias } & \multirow{2}{*}{$\begin{array}{l}\text { Pessoas } \\
\text { por } \\
\text { família }\end{array}$} & \multirow{2}{*}{$\begin{array}{c}\text { Renda } \\
\text { familiar } \\
\text { per capita } \\
\left(\mathbf{R}^{*}\right)\end{array}$} & \multirow{2}{*}{$\begin{array}{c}\% \text { da } \\
\text { renda } \\
\text { total na } \\
\text { classe }\end{array}$} \\
\hline & $\begin{array}{c}\text { Número } \\
\text { (mil) }\end{array}$ & $(\%)$ & $\begin{array}{l}\text { Número } \\
\text { (mil) }\end{array}$ & $(\%)$ & & & \\
\hline 0,40 & & 1420 & & 1 & 4,27 & 4 & 2,05 \\
\hline Iai & & 17 & & 13 & 2 & & 5,18 \\
\hline Iais & 2 & 15 & 9 & & 6 & & 7,12 \\
\hline [ais & 2 & 12 , & 8.7 & & 0 & & 7,77 \\
\hline [ais & 8 & 9,09 & 7.073 & 10,25 & 2,66 & & 7,25 \\
\hline Iais & & 8 , & 6.563 & & 2,59 & & 8,09 \\
\hline Iais & 353 & 10,3 & 8.717 & 12 , & 2,45 & & 13,79 \\
\hline lais & 15.268 & & 6.307 & & 2,42 & & 15,40 \\
\hline Iais & 8.694 & 4, & 3.861 & 5 , & 2,25 & 6.8 & 15,95 \\
\hline Mais d & 3.686 & 1,78 & 1.795 & 2,60 & 2,05 & $17.692,01$ & 17,41 \\
\hline Total & 207.104 & 100 & 69.018 & 100 & 3,00 & 1.808 .46 & 100 \\
\hline
\end{tabular}

Após calcularem-se as despesas per capita médias com um determinado alimento nas dez classes da RFPC consideradas, esses valores foram utilizados para se estimar, por mínimos quadrados ponderados, uma função poligonal com três segmentos (dois vértices), conforme o modelo: 


$$
\ln Y_{i}=\alpha+\beta \ln X_{i}+\sum_{h=1}^{2} \delta_{h} Z_{h i}\left(\ln X_{i}-\ln \theta_{h}\right)+u_{i}, \quad i=1, \ldots, 10
$$

em que $Y_{i}$ é a despesa per capita média na $i$-ésima classe e $X_{i}$ a RFPC correspondente. Cada um dos dez pontos é ponderado pelo número de pessoas da população que pertence à respectiva classe.

Nessa especificação, $\theta_{h}$ denota a RFPC correspondente ao $h$-ésimo vértice da poligonal (com $\left.\theta_{1}<\theta_{2}\right), Z_{h i}$ é uma variável binária igual a zero para $X_{i} \leq$ $\theta_{h}$ e igual a 1 para $X_{i}>\theta_{h}$ e $u_{i}$ é o termo estocástico do modelo. Os três segmentos da poligonal correspondem a três grandes estratos (que serão indicados por I, II e III) delimitados por $\theta_{1}$ e $\theta_{2}$. No estrato I, $\operatorname{com} X_{i} \leq \theta_{1}$, a elasticidade-renda é igual a $\beta$; no estrato II, com $\theta_{1}<X_{i} \leq \theta_{2}$, a elasticidaderenda é $\beta+\delta_{1}$; e no estrato III, com $X_{i}>\theta_{2}$, a elasticidade-renda é igual a $\beta+$ $\delta_{1}+\delta_{2}($ HOFFMANN, 2010).

Podem-se adotar como valores para $\theta_{1}$ e $\theta_{2}$ dois dos nove limites que definem as dez classes de renda apresentadas na Tabela 2. Combinados dois a dois, esses nove limites formam $\frac{9 \times 8}{2 !}=36$ combinações, correspondentes a 36 diferentes maneiras de se ajustar uma poligonal com três segmentos. O ajustamento adotado foi aquele que resultou no maior coeficiente de determinação do modelo $\left(R^{2}\right)$, salvo no caso de categorias de despesas em que a estimativa da elasticidade em algum dos três estratos mostrou-se claramente discrepante, particularmente no caso de estratos que incluíam apenas uma classe de renda. Nesses casos, escolheuse outra forma de agrupamento, desde que isso não reduzisse muito o $R^{2}$.

Após se estimarem as elasticidades-renda nos três estratos, correspondentes aos três segmentos do modelo de poligonal adotado, a elasticidade-renda média foi obtida mediante a média ponderada dessas três elasticidades, adotando-se como fator de ponderação a participação de cada estrato na despesa analisada. Se $\varepsilon_{h}$, com $h=1,2$ ou 3, é a elasticidade-renda da despesa no $h$-ésimo estrato e $\varphi_{h}$ é a participação do estrato no total desse tipo de despesa, pode-se demonstrar que a elasticidade-renda média da despesa considerada é dada por:

$$
\varepsilon=\sum_{h=1}^{3} \varepsilon_{h} \varphi_{h}
$$


Essa lógica também se aplica à elasticidade-renda de uma soma de $k$ tipos de despesa. Seja $\varepsilon_{j}$ a elasticidade-renda do $j$-ésimo tipo de despesa e seja $\varphi_{j}$ sua participação na despesa total, com $j=1, \ldots, k$. Então, a elasticidade-renda da despesa total $(\varepsilon)$ é dada por:

$$
\varepsilon=\sum_{j=1}^{k} \varepsilon_{j} \varphi_{j}
$$

Cabe ressaltar, entretanto, que o método de estimação baseado nas poligonais não garante a obediência exata dessa relação. Se uma poligonal for ajustada aos dados sobre a despesa total, a elasticidade-renda média estimada não será, necessariamente, igual ao valor dado pela expressão (3), obtido a partir das elasticidades médias para cada tipo de despesa que compõe o agregado.

\subsubsection{Curvas e razões de concentração}

Para o cálculo das razões e curvas de concentração, ordenaram-se os indivíduos segundo valores não decrescentes da renda familiar per capita (RFPC). Definiu-se a proporção acumulada da população até a $i$-ésima pessoa como $p_{i}=$ $i / n$, em que $n$ indica o tamanho da população. Calculou-se, então, a proporção acumulada, até o $i$-ésimo indivíduo, da despesa familiar per capita $(Y)$ com determinado alimento, mediante a expressão

$$
\Psi_{i}=\frac{1}{n \mu_{Y}} \sum_{j=1}^{i} Y_{j}
$$

em que $\mu_{Y}$ é a despesa familiar per capita média.

A curva formada pela origem e pelos pontos $\left(p_{i}, \Psi_{i}\right)$ é a curva de concentração da despesa em relação à renda. Seja $\beta_{i}$ a área compreendida entre essa curva e o eixo das abscissas. Então, a razão de concentração da despesa é dada por

$$
\mathrm{C}_{Y}=1-2 \beta_{Y}
$$

Note-se que, embora a variável de interesse seja a despesa, os dados são ordenados conforme valores não decrescentes da RFPC. O índice de Gini é o caso particular da razão de concentração em que a proporção acumulada da variável de interesse é ordenada por ela mesma. Assim, neste trabalho o índice de Gini é 
obtido ao se adotar como variável de interesse na expressão (4) a renda familiar per capita.

É possível demonstrar que

$$
-1+\frac{1}{n} \leq C_{Y} \leq 1-\frac{1}{n}
$$

Um valor elevado (próximo de 1) de $C_{Y}$ indica que a despesa está concentrada nos relativamente ricos, ao passo que um valor baixo (próximo de 1) indica que ela está concentrada nos pobres. Despesas com razão de concentração superior ao índice de Gini estão mais concentradas nos relativamente ricos do que a própria renda.

É importante destacar que uma razão de concentração nula não implica que a distribuição da despesa seja igualitária. Esse valor indica tão somente que não há associação linear entre a despesa e a renda na população, embora possa haver substancial desigualdade na distribuição de ambas. Para medir a desigualdade da distribuição da despesa, deve-se calcular seu índice de Gini, o que requer ordenar previamente a população segundo valores não decrescentes dessa variável.

Kakwani (1977) demonstrou a relação direta existente entre a elasticidaderenda de uma despesa e sua curva de concentração: uma despesa com elasticidaderenda sempre menor (maior) do que um terá sua curva de concentração posicionada acima (abaixo) da curva de Lorenz. Se a elasticidade for negativa, a curva de concentração ficará acima da bissetriz do primeiro quadrante.

\section{Resultados}

\subsection{Evolução da despesa média com alimentos}

A Tabela 3 apresenta a despesa média mensal familiar com alimentação no domicílio e fora dele, a preços constantes de janeiro de 2018, de acordo com as edições de 2002-2003, 2008-2009 e 2017-2018 da POF.

Conforme se vê, a despesa total com alimentação, apresentada na última coluna da tabela, manteve uma trajetória declinante, passando de $\mathrm{R} \$ 714,36 \mathrm{em}$ 2002-2003, para R\$ 711,91 em 2008-2009 e R\$ 658,23 em 2017-2018. Contudo, ao se desagregar esses valores nas parcelas referentes à alimentação dentro e fora do domicílio, observam-se diferenças importantes. A variação nos gastos com alimentação no domicílio conservou - tanto em sinal como em magnitude -, seu 
comportamento, declinando 9,65\% em 2008-2009 e 9,78\% em 2017-2018, considerando sempre a variação em relação à $\mathrm{POF}$ anterior. Em contrapartida, o gasto com alimentação fora do domicílio, cujo forte crescimento - da ordem de 29\% - entre as POF 2002-2003 e 2008-2009 havia sido reportado na literatura, interrompeu sua trajetória ascendente, tendo decrescido 2,59\% em 2017-2018. Esse resultado é explicado pela crise econômica que atingiu o País a partir de meados de 2014. Quando os dados da POF 2017-2018 começaram a ser coletados, em junho de 2017, a taxa de desemprego no País era de $13 \%$, em contraste com o valor de 6,8\% observado três anos antes, de acordo com os dados da Pesquisa Nacional por Amostra de Domicílios Contínua do IBGE.

Tabela 3 - Despesa mensal média por família com alimentação dentro e fora do domicílio, em R\$ de jan. de 2018, Brasil, 2002/2018

\begin{tabular}{l|r|r|r}
\hline \multicolumn{1}{c|}{ Despesa média mensal por família } & $\begin{array}{c}\text { Alimentação } \\
\text { no domicílio }\end{array}$ & $\begin{array}{c}\text { Alimentação } \\
\text { fora do } \\
\text { domicílio }\end{array}$ & $\begin{array}{c}\text { Alimentação } \\
\text { total }\end{array}$ \\
\hline & & & \\
POF 2002-2003 & 542,56 & 171,80 & 714,36 \\
POF 2008-2009 & 490,21 & 221,70 & 711,91 \\
POF 2017-2018 & 442,27 & 215,96 & 658,23 \\
Variação 2008-2009/2002-2003 (\%) & $-9,65$ & 29,05 & $-0,34$ \\
Variação 2017-2018/2008-2009(\%) & $-9,78$ & $-2,59$ & $-7,54$ \\
\hline
\end{tabular}

Fonte: elaborada pelos autores com dados da Pesquisa de Orçamentos Familiares (POF/IBGE).

A Tabela 4, a seguir, detalha os gastos segundo as categorias de alimentos definidas pelo IBGE. Em se tratando da alimentação no domicílio, os dados da POF 2017-2018 mostram uma redução nos dispêndios com alimentos tradicionais, em particular arroz $(-43,98 \%)$, feijão $(-55,47 \%)$, macarrão com ovos $(-41,97 \%)$, farinha de trigo $(-52,41 \%)$, farinha de mandioca $(-34,13 \%)$, leite de vaca $(-38,71 \%)$ e óleo de soja $(-46,65 \%)$. Essa redução acompanha a tendência e, na maior parte dos casos, a magnitude da queda que já vinha sendo observada ao se compararem as edições da POF de 2002-2003 e 2008-2009.

Nota-se, por outro lado, a reversão na tendência de aumento dos gastos com carnes, vísceras e pescados, que foram parcialmente contrabalançados pelo aumento do gasto com fontes proteicas mais baratas. $O$ dispêndio médio com carne de boi de primeira, por exemplo, caiu $15,03 \%$, embora houvesse aumentado no 
período anterior. Até mesmo o consumo de carne de boi de segunda declinou. Em contrapartida, o gasto com ovo de galinha, que havia declinado $23,84 \%$ em 2008 2009, elevou-se 20,34\% em 2017-2018. O único tipo de carne cujos gastos aumentaram foi a de suíno.

Outros alimentos cuja trajetória de gastos foi revertida na POF 2017-2018 foram macarrão sem ovos e açúcar. Os dados da Tabela 4 mostram uma queda de $80,82 \%$ no gasto com açúcar refinado e de 74,53\% com açúcar cristal entre 20022003 e 2008-2009. Souza, Oliveira e Burnquist (2013) mostram que nesse período o aumento na renda levou à redução do consumo per capita de açúcar, que foi substituído pelo consumo de produtos industrializados que usam açúcar em sua composição. Porém, em 2017-2018 a trajetória declinante foi interrompida e os gastos com açúcar voltaram a aumentar, ainda que os valores sejam muito inferiores aos observados no início da série.

Cumpre notar, ainda, que os gastos com todas as categorias de produtos light e diet apresentaram queda em 2017-2018: açúcares e derivados light e diet ($68,57 \%)$, leites e derivados light e diet (-19,88\%), panificados light e diet ($53,57 \%)$ e bebidas não alcoólicas light e diet $(-61,48 \%)$.

Com relação à alimentação fora do domicílio, merece destaque o fato de que os gastos com almoço e jantar, que haviam quase dobrado de valor entre 20022003 e 2008-2009, tiveram um crescimento fraco na última POF (5,05\%), que pode ser associado à crise econômica observada no País. Por outro lado, o dispêndio com cervejas, chopes e outras bebidas alcoólicas fora do domicílio continuou caindo (-35,73\%), seguindo o comportamento observado na POF 2008$2009(-34,58 \%)$. Essa queda contrasta com o aumento do gasto com cervejas e chopes $(+11,30 \%)$ e outras bebidas alcoólicas $(+14,47 \%)$ consumidos dentro do domicílio e pode estar associada à mudança nos hábitos da população brasileira em relação ao uso de álcool e direção. Malta et al. (2014) mostram ter havido, de 2007 a 2013, uma redução de $45 \%$ na frequência de adultos que dirigiram após o consumo abusivo de álcool nas capitais dos 26 estados brasileiros e do Distrito Federal. As reduções mais expressivas foram observadas nos anos que sucederam a aprovação das leis federais que pró́bem dirigir alcoolizado, a saber, a Lei 11.705/2008, conhecida como Lei Seca, e a Lei 12.760/2012, ou nova Lei Seca, que aperfeiçoou o marco regulatório e ampliou as sanções. 
Tabela 4 - Despesa mensal média por família e elasticidade-renda da despesa com alimentos, Brasil, $2002 / 2018$

(continua)

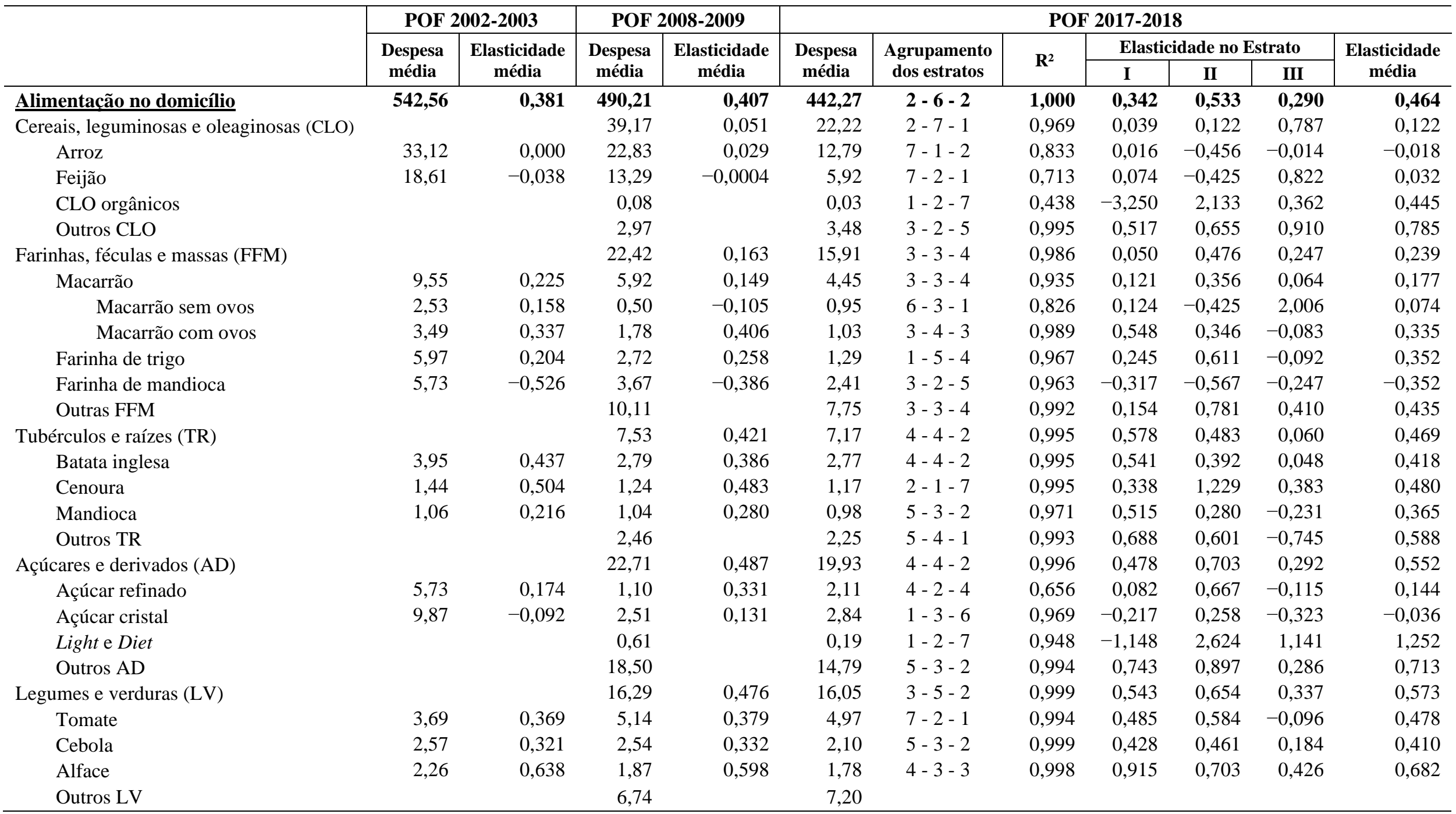

Fonte: elaborada pelos autores com dados da Pesquisa de Orçamentos Familiares (POF/IBGE). 
Tabela 4 - Despesa mensal média por família e elasticidade-renda da despesa com alimentos, Brasil, 2002/2018

(continua)

\begin{tabular}{|c|c|c|c|c|c|c|c|c|c|c|c|}
\hline & \multicolumn{2}{|c|}{ POF 2002-2003 } & \multicolumn{2}{|c|}{ POF 2008-2009 } & \multicolumn{7}{|c|}{ POF 2017-2018 } \\
\hline & \multirow{2}{*}{$\begin{array}{l}\text { Despesa } \\
\text { média }\end{array}$} & \multirow{2}{*}{$\begin{array}{l}\text { Elasticidade } \\
\text { média }\end{array}$} & \multirow{2}{*}{$\begin{array}{l}\text { Despesa } \\
\text { média }\end{array}$} & \multirow{2}{*}{$\begin{array}{l}\text { Elasticidade } \\
\text { média }\end{array}$} & \multirow{2}{*}{$\begin{array}{l}\text { Despesa } \\
\text { média }\end{array}$} & \multirow{2}{*}{$\begin{array}{c}\text { Agrupamento } \\
\text { dos estratos }\end{array}$} & \multirow{2}{*}{$\mathbf{R}^{2}$} & \multicolumn{3}{|c|}{ Elasticidade no Estrato } & \multirow{2}{*}{$\begin{array}{l}\text { Elasticidade } \\
\text { média }\end{array}$} \\
\hline & & & & & & & & $\mathbf{I}$ & II & III & \\
\hline Frutas & & & 22,66 & 0,633 & 23,08 & $3-4-3$ & 0,998 & 0,626 & 0,905 & 0,416 & 0,681 \\
\hline Banana & 5,21 & 0,374 & 5,51 & 0,456 & 5,94 & $2-2-6$ & 0,997 & 0,517 & 0,851 & 0,436 & 0,543 \\
\hline Laranja & 3,29 & 0,585 & 2,74 & 0,590 & 2,37 & $3-3-4$ & 0,994 & 0,674 & 1,103 & 0,342 & 0,646 \\
\hline Maçã & 2,76 & 0,651 & 2,97 & 0,608 & 2,35 & $3-3-4$ & 0,993 & 0,595 & 0,996 & 0,346 & 0,603 \\
\hline Outras frutas & & & 11,45 & & 12,42 & $3-4-3$ & 0,998 & 0,628 & 1,062 & 0,502 & 0,767 \\
\hline Limão & 0,48 & 0,628 & 0,46 & 0,731 & 0,81 & $4-2-4$ & 0,990 & 0,798 & 1,846 & 0,454 & 0,823 \\
\hline Tangerina & 1,32 & 0,706 & 0,76 & 0,691 & 0,72 & $1-7-2$ & 0,997 & 0,378 & 1,127 & 0,030 & 0,868 \\
\hline Abacaxi & 0,78 & 0,714 & 0,86 & 0,730 & 0,84 & $3-4-3$ & 0,990 & 0,685 & 0,941 & 0,385 & 0,696 \\
\hline Abacate & 0,23 & 0,333 & 0,25 & 0,424 & 0,45 & $4-3-3$ & 0,992 & 0,775 & 1,100 & 0,694 & 0,841 \\
\hline Caqui & 0,16 & 1,035 & 0,20 & 0,936 & 0,19 & $1-2-7$ & 0,971 & 5,283 & 0,039 & 1,078 & 0,945 \\
\hline Mamão & 1,53 & 0,882 & 1,63 & 0,940 & 1,48 & $2-5-3$ & 0,997 & 0,268 & 1,408 & 0,627 & 0,955 \\
\hline Manga & 0,91 & 0,468 & 0,84 & 0,598 & 1,09 & $3-4-3$ & 0,981 & 0,566 & 1,055 & 0,259 & 0,694 \\
\hline Melancia & 1,34 & 0,560 & 1,33 & 0,445 & 1,10 & $5-2-3$ & 0,969 & 0,585 & 0,835 & 0,156 & 0,541 \\
\hline Melão & 0,39 & 0,939 & 0,46 & 0,879 & 0,71 & $5-2-3$ & 0,991 & 0,834 & 1,495 & 0,700 & 0,936 \\
\hline Pera & 0,60 & 1,114 & 0,76 & 0,954 & 0,67 & $6-3-1$ & 0,995 & 1,224 & 0,904 & $-0,218$ & 0,929 \\
\hline Pêssego & 0,24 & 1,203 & 0,27 & 0,968 & 0,23 & $2-1-7$ & 0,989 & 0,255 & 3,771 & 0,916 & 1,031 \\
\hline Ameixa & 0,17 & 1,097 & 0,26 & 1,045 & 0,26 & $2-6-2$ & 0,997 & 1,625 & 1,240 & 0,162 & 0,992 \\
\hline Uva & 1,17 & 0,837 & 1,32 & 0,795 & 1,45 & $1-2-7$ & 0,978 & 1,257 & 0,057 & 0,813 & 0,689 \\
\hline Morango & & & 0,52 & 1,000 & 0,54 & $1-6-3$ & 0,982 & 0,816 & 1,671 & 0,238 & 1,018 \\
\hline Carnes, vísceras e pescados (CVP) & & & 107,28 & 0,365 & 89,42 & $2-5-3$ & 0,995 & 0,275 & 0,522 & 0,182 & 0,395 \\
\hline Carne de boi de primeira & 27,10 & 0,588 & 28,79 & 0,588 & 24,46 & $2-4-4$ & 0,989 & 0,575 & 1,018 & 0,475 & 0,696 \\
\hline Carne de boi de segunda & 20,79 & 0,147 & 21,22 & 0,183 & 16,38 & $2-5-3$ & 0,982 & 0,306 & 0,388 & $-0,302$ & 0,253 \\
\hline Carne de suíno & & & 4,82 & 0,477 & 7,61 & $6-3-1$ & 0,995 & 0,541 & 0,000 & 0,623 & 0,379 \\
\hline Carnes e peixes industrializados & & & 24,08 & & 19,35 & $2-6-2$ & 0,996 & 0,290 & 0,530 & 0,075 & 0,428 \\
\hline Mortadela & 2,00 & 0,233 & 2,38 & 0,209 & 1,67 & $3-3-4$ & 0,860 & $-0,094$ & 0,828 & $-0,123$ & 0,180 \\
\hline Presunto & 2,45 & 0,999 & 2,46 & 0,841 & 2,04 & $4-4-2$ & 0,997 & 1,097 & 0,825 & 0,162 & 0,776 \\
\hline Pescados frescos & & & 8,51 & 0,086 & 7,12 & $1-6-3$ & 0,803 & $-0,620$ & 0,082 & 0,461 & 0,039 \\
\hline Outras CVP & & & 19,86 & & 14,50 & $4-4-2$ & 0,936 & 0,249 & 0,145 & $-0,344$ & 0,168 \\
\hline
\end{tabular}

Fonte: elaborada pelos autores com dados da Pesquisa de Orçamentos Familiares (POF/IBGE). 
Tabela 4 - Despesa mensal média por família e elasticidade-renda da despesa com alimentos, Brasil, 2002/2018

(continua)

\begin{tabular}{|c|c|c|c|c|c|c|c|c|c|c|c|}
\hline & \multicolumn{2}{|c|}{ POF 2002-2003 } & \multicolumn{2}{|c|}{ POF 2008-2009 } & \multicolumn{7}{|c|}{ POF 2017-2018 } \\
\hline & \multirow{2}{*}{$\begin{array}{l}\text { Despesa } \\
\text { média }\end{array}$} & \multirow{2}{*}{$\begin{array}{c}\text { Elasticidade } \\
\text { média }\end{array}$} & \multirow{2}{*}{$\begin{array}{c}\text { Despesa } \\
\text { média }\end{array}$} & \multirow{2}{*}{$\begin{array}{l}\text { Elasticidade } \\
\text { média }\end{array}$} & \multirow{2}{*}{$\begin{array}{l}\text { Despesa } \\
\text { média }\end{array}$} & \multirow{2}{*}{$\begin{array}{c}\text { Agrupamento } \\
\text { dos estratos }\end{array}$} & \multirow{2}{*}{$\mathbf{R}^{2}$} & \multicolumn{3}{|c|}{ Elasticidade no Estrato } & \multirow{2}{*}{$\begin{array}{l}\text { Elasticidade } \\
\text { média }\end{array}$} \\
\hline & & & & & & & & $\mathbf{I}$ & II & III & \\
\hline Aves e ovos & & & 33,86 & 0,201 & 33,58 & $4-5-1$ & 0,996 & 0,153 & 0,293 & $-0,176$ & 0,208 \\
\hline Frango & 29,56 & 0,211 & 26,93 & 0,179 & 24,76 & $6-3-1$ & 0,986 & 0,114 & 0,230 & $-0,295$ & 0,135 \\
\hline Ovo de galinha & 7,84 & 0,271 & 5,97 & 0,194 & 7,18 & $2-6-2$ & 0,997 & 0,257 & 0,385 & 0,122 & 0,329 \\
\hline Aves e ovos orgânicos & & & 0,20 & 1,184 & 0,11 & $2-3-5$ & 0,690 & 1,285 & 0,239 & 1,774 & 1,501 \\
\hline Outros aves e ovos & & & 0,76 & & 1,53 & $3-5-2$ & 0,982 & 0,400 & 1,067 & 0,230 & 0,733 \\
\hline Leites e derivados & & & 56,16 & 0,515 & 46,93 & $4-4-2$ & 0,999 & 0,500 & 0,738 & 0,199 & 0,563 \\
\hline Leite de vaca & 29,62 & 0,441 & 23,61 & 0,393 & 14,47 & $3-2-5$ & 0,999 & 0,518 & 0,615 & 0,191 & 0,391 \\
\hline Leite em pó & 7,58 & 0,047 & 5,84 & 0,108 & 5,56 & $6-2-2$ & 0,666 & $-0,039$ & 0,475 & $-0,154$ & 0,054 \\
\hline Queijos & 11,30 & 0,908 & 11,48 & 0,853 & 12,82 & $2-6-2$ & 0,998 & 0,852 & 1,142 & 0,244 & 0,897 \\
\hline Queijo prato & 2,16 & 0,935 & 1,83 & 0,842 & 1,61 & $2-5-3$ & 0,991 & 0,834 & 1,501 & 0,300 & 0,962 \\
\hline Queijo mozarela & 2,79 & 0,929 & 3,70 & 0,843 & 4,68 & $1-6-3$ & 0,996 & 0,728 & 1,166 & 0,312 & 0,828 \\
\hline Queijo minas & & & 3,13 & 0,746 & 2,99 & $4-4-2$ & 0,992 & 0,636 & 1,237 & 0,226 & 0,824 \\
\hline Light e Diet & & & 0,95 & & 0,76 & $2-1-7$ & 0,975 & 0,839 & 3,115 & 1,189 & 1,254 \\
\hline Orgânicos & & & 0,27 & & 0,13 & $4-2-4$ & 0,648 & $-0,041$ & 4,501 & 1,007 & 1,327 \\
\hline Outros & & & 14,00 & & 13,18 & $5-3-2$ & 0,998 & 0,579 & 0,856 & 0,022 & 0,596 \\
\hline Iogurte & 4,54 & 0,674 & 4,31 & 0,628 & 3,50 & $4-4-2$ & 0,997 & 0,495 & 0,991 & 0,222 & 0,675 \\
\hline Leite condensado & 1,62 & 0,706 & 1,68 & 0,614 & 1,64 & $2-5-3$ & 0,997 & 0,959 & 0,631 & 0,138 & 0,548 \\
\hline Manteiga & 1,58 & 0,592 & 1,20 & 0,661 & 2,08 & $2-7-1$ & 0,993 & 0,245 & 1,223 & $-0,935$ & 0,958 \\
\hline Margarina & 5,20 & 0,345 & 4,16 & 0,292 & 2,65 & $7-2-1$ & 0,982 & 0,310 & $-0,199$ & $-0,919$ & 0,221 \\
\hline Panificados & & & 51,07 & 0,380 & 45,34 & $1-7-2$ & 0,999 & 0,247 & 0,456 & 0,178 & 0,406 \\
\hline Pão francês & 31,02 & 0,343 & 24,31 & 0,244 & 18,62 & $4-5-1$ & 0,995 & 0,333 & 0,126 & $-0,144$ & 0,225 \\
\hline Biscoito & & & 13,17 & & 11,89 & $4-3-3$ & 0,988 & 0,254 & 0,451 & 0,189 & 0,304 \\
\hline Light e Diet & & & 0,45 & & 0,21 & $1-7-2$ & 0,958 & $-0,680$ & 1,543 & 0,856 & 1,229 \\
\hline Outros panificados & & & 13,15 & & 14,61 & $1-7-2$ & 0,996 & 0,231 & 0,881 & 0,168 & 0,719 \\
\hline Óleos e gorduras & & & 11,13 & 0,277 & 7,40 & $3-6-1$ & 0,996 & 0,294 & 0,527 & 0,194 & 0,437 \\
\hline Óleo de soja & 14,77 & 0,086 & 8,20 & 0,073 & 4,38 & $7-1-2$ & 0,974 & 0,170 & $-1,189$ & 0,132 & 0,069 \\
\hline Azeite de oliva & 1,29 & 1,170 & 1,49 & 1,059 & 1,91 & $1-8-1$ & 0,998 & 1,636 & 1,264 & $-0,133$ & 1,074 \\
\hline Outros & & & 1,43 & & 1,11 & $1-7-2$ & 0,990 & 0,001 & 0,961 & 0,214 & 0,754 \\
\hline
\end{tabular}

Fonte: Elaborada pelos autores com dados da Pesquisa de Orçamentos Familiares (POF/IBGE). 
Tabela 4 - Despesa mensal média por família e elasticidade-renda da despesa com alimentos, Brasil, 2002/2018

(conclusão)

\begin{tabular}{|c|c|c|c|c|c|c|c|c|c|c|c|}
\hline & \multicolumn{2}{|c|}{ POF 2002-2003 } & \multicolumn{2}{|c|}{ POF 2008-2009 } & \multicolumn{7}{|c|}{ POF 2017-2018 } \\
\hline & \multirow{2}{*}{$\begin{array}{l}\text { Despesa } \\
\text { média }\end{array}$} & \multirow{2}{*}{$\begin{array}{l}\text { Elasticidade } \\
\text { média }\end{array}$} & \multirow{2}{*}{$\begin{array}{c}\text { Despesa } \\
\text { média }\end{array}$} & \multirow{2}{*}{$\begin{array}{c}\text { Elasticidade } \\
\text { média }\end{array}$} & \multirow{2}{*}{$\begin{array}{c}\text { Despesa } \\
\text { média }\end{array}$} & \multirow{2}{*}{$\begin{array}{c}\text { Agrupamento } \\
\text { dos estratos }\end{array}$} & \multirow{2}{*}{$\mathbf{R}^{2}$} & \multicolumn{3}{|c|}{ Elasticidade no Estrato } & \multirow{2}{*}{$\begin{array}{c}\text { Elasticidade } \\
\text { média }\end{array}$} \\
\hline & & & & & & & & $\mathbf{I}$ & II & III & \\
\hline Bebidas e infusões & & & 47,36 & 0,563 & 47,02 & $2-6-2$ & 0,999 & 0,418 & 0,766 & 0,346 & 0,641 \\
\hline Café moído & 9,25 & 0,166 & 9,57 & 0,218 & 9,92 & $1-6-3$ & 0,992 & 0,115 & 0,306 & 0,121 & 0,252 \\
\hline Refrigerantes & & & 16,29 & 0,540 & 12,04 & $1-6-3$ & 0,997 & 0,443 & 0,717 & 0,227 & 0,566 \\
\hline Bebidas não alcoólicas light e diet & & & 0,96 & 1,203 & 0,37 & $3-2-5$ & 0,970 & 1,678 & 2,742 & 1,301 & 1,464 \\
\hline Cervejas e chopes & 8,56 & 0,811 & 9,02 & 0,784 & 10,04 & $1-6-3$ & 0,991 & 0,202 & 1,388 & 0,318 & 0,915 \\
\hline Outras bebidas alcoólicas & & & 3,27 & & 3,74 & $3-6-1$ & 0,970 & 0,930 & 1,490 & $-0,322$ & 1,160 \\
\hline Vinho & 1,66 & 0,996 & 1,87 & 1,289 & 2,17 & $1-2-7$ & 0,974 & 3,256 & 0,558 & 1,634 & 1,581 \\
\hline Aguardente de cana/caipirinha & 0,40 & 0,260 & 0,35 & 0,074 & 0,37 & $1-2-7$ & 0,939 & 1,728 & 0,345 & 0,463 & 0,490 \\
\hline Enlatados e conservas & & & 4,48 & 0,697 & 3,89 & $3-4-3$ & 0,979 & 0,305 & 1,097 & 0,449 & 0,692 \\
\hline Sal e condimentos & & & 10,66 & 0,438 & 10,19 & $3-4-3$ & 0,998 & 0,532 & 0,578 & 0,270 & 0,486 \\
\hline Massa de tomate & & & 1,63 & 0,328 & 0,76 & $1-5-4$ & 0,973 & 1,097 & 0,461 & 0,048 & 0,356 \\
\hline Maionese & 1,66 & 0,646 & 1,05 & 0,608 & 1,02 & $1-6-3$ & 0,994 & 1,374 & 0,755 & 0,174 & 0,614 \\
\hline Sal refinado & 0,97 & 0,078 & 0,73 & 0,067 & 0,50 & $3-1-6$ & 0,898 & 0,144 & 1,046 & $-0,001$ & 0,186 \\
\hline Outros & & & 7,24 & & 7,91 & $3-4-3$ & 0,999 & 0,510 & 0,598 & 0,319 & 0,498 \\
\hline Alimentos preparados & & & 14,25 & 0,824 & 14,90 & $2-6-2$ & 0,996 & 0,718 & 1,060 & 0,136 & 0,822 \\
\hline Outros alimentos & & & 23,16 & & 39,24 & $2-6-2$ & 0,990 & 0,816 & 0,355 & 0,728 & 0,489 \\
\hline Alimentacão fora do domicílio & $\mathbf{1 7 1 , 8 0}$ & 0,798 & 221,70 & $\mathbf{0 , 8 2 8}$ & 215,96 & $4-5-1$ & 0,999 & 0,798 & 0,844 & 0,449 & $\mathbf{0 , 7 8 9}$ \\
\hline$\overline{\text { Almoço e jantar }}$ & 71,76 & 1,043 & 138,95 & 0,763 & 145,97 & $3-5-2$ & 1,000 & 0,942 & 1,025 & 0,706 & 0,920 \\
\hline Café, leite, café/leite e chocolate & & & & & 2,50 & $4-3-3$ & 0,997 & 0,649 & 1,130 & 0,644 & 0,800 \\
\hline Sanduíches e salgados & & & & & 18,28 & $1-6-3$ & 0,997 & 0,477 & 0,866 & 0,284 & 0,666 \\
\hline Refrigerantes e outras bebidas não alc. & & & & & 7,25 & $1-6-3$ & 0,999 & 0,472 & 0,547 & 0,227 & 0,462 \\
\hline Lanches & & & & & 15,82 & $1-6-3$ & 0,994 & 0,820 & 0,416 & 0,735 & 0,534 \\
\hline Cervejas, chopes e outras bebidas alc. & 23,84 & 0,561 & 15,60 & $-1,301$ & 10,03 & $3-6-1$ & 0,979 & 0,701 & 0,604 & $-0,480$ & 0,579 \\
\hline Vinho & & & & & & $6-3-1$ & 0,906 & 1,108 & 2,489 & $-2,657$ & 1,816 \\
\hline Aguardente & & & & & & $8-1-1$ & 0,816 & 0,121 & $-3,915$ & 4,778 & 0,165 \\
\hline Alimentação light e diet & & & & & 0,12 & $3-1-6$ & 0,894 & 0,427 & 2,208 & 1,089 & 1,046 \\
\hline ALIMENTAÇÃO TOTAL & 714,36 & & 711,91 & & 658,23 & $2-7-1$ & 1,000 & $\mathbf{0 , 4 4 2}$ & 0,620 & $\mathbf{0 , 2 9 3}$ & $\mathbf{0 , 5 7 0}$ \\
\hline
\end{tabular}

Fonte: Elaborada pelos autores com dados da Pesquisa de Orçamentos Familiares (POF/IBGE). 


\subsection{Elasticidades-renda da despesa com alimentos}

A Tabela 4 mostra, para cada uma das categorias de alimentos definidas pelo IBGE, os resultados obtidos para o ajustamento da função poligonal que relaciona o logaritmo da despesa per capita ao logaritmo da renda per capita nas dez classes de renda definidas na seção 3.2.1. Nessa tabela é possível observar, para a POF 2017-2018, o esquema de agrupamento das dez classes de RFPC, o coeficiente de determinação $\left(\mathrm{R}^{2}\right)$ do modelo, as elasticidades para cada um dos grandes estratos (I, II e III) e a elasticidade média.

Para a maior parte dos alimentos o ajuste da função aos dados é quase perfeito, com $\mathrm{R}^{2}$ maior que 0,9 , o que indica que as variações na renda explicam mais de $90 \%$ da variabilidade observada nas despesas médias nas dez classes.

Cumpre destacar que se uma despesa é a soma de $k$ parcelas, sua elasticidade-renda deve ser igual à média ponderada das elasticidades-renda médias das parcelas, de acordo com a equação (3) apresentada anteriormente. As elasticidades-renda médias estimadas por meio do ajuste das poligonais obedecem a essa condição apenas de maneira aproximada. Verifica-se, por exemplo, que a média ponderada das elasticidades-renda médias das 16 categorias que compõem a alimentação no domicílio é igual a 0,46437, ao passo que a elasticidade média estimada por meio do ajuste de uma poligonal ao total de despesas com alimentação no domicílio é de 0,46389 . Neste trabalho serão comentadas as elasticidades estimadas por meio do ajuste da poligonal, que se encontram reportadas na tabela 4 .

A elasticidade-renda média das despesas com alimentação fora do domicílio é muito maior do que a relativa à alimentação no domicílio. Os valores obtidos indicam que um aumento de $10 \%$ na renda ocasionaria um aumento na despesa com alimentação fora do domicílio de 7,89\%, mas de apenas 4,64\% nas despesas com alimentação no domicílio. Isso se explica pelo fato de a alimentação fora do domicílio estar, muitas vezes, associada às atividades de lazer.

Verifica-se que arroz, farinha de mandioca, açúcar cristal e óleo de soja possuem elasticidade-renda muito baixa, e, a depender do estrato considerado, negativa, o que os caracteriza como bens inferiores. É oportuno observar que o valor da elasticidade em um dos três estratos pode ser pouco confiável se a estimativa estiver associada a uma única classe de RFPC. Por exemplo, a elasticidade-renda do feijão passa de $-0,4246$ no segundo estrato para 0,8216 no 
terceiro, porém, essa estimativa foi obtida com base em apenas uma das dez classes de renda, o que a torna pouco confiável, em razão de variações aleatórias associadas à amostragem. Nesse caso, a elasticidade média é mais fidedigna, com precisão tanto maior quanto maior for o coeficiente de determinação da regressão.

Hoffmann (2010) havia notado, com base na POF 2008-2009, que a elasticidade-renda da farinha de mandioca era negativa nos três segmentos da poligonal ajustada. Esse resultado se repete ao se considerarem os dados da POF 2017-2018, sendo a elasticidade-renda média fortemente negativa $(-0,352)$.

Entre os alimentos com elasticidade-renda média maior que a unidade estão: o pêssego, o morango, aves e ovos orgânicos, leites e derivados light e diet e orgânicos, panificados light e diet, azeite de oliva, bebidas não alcoólicas light e diet, vinho consumido dentro e fora do domicílio e alimentação light e diet fora do domicílio. Para esses bens, ditos superiores, um crescimento proporcional da renda de todos os brasileiros causaria um aumento mais que proporcional nos gastos. Oliveira e Hoffmann (2015) compararam as elasticidades-renda das despesas de diversos tipos de alimentos orgânicos e light/diet com as elasticidades de seus correlatos convencionais, com base nos dados da POF 2008-2009, verificando que os primeiros apresentam valores sistematicamente maiores.

Cumpre destacar alguns alimentos para os quais a elasticidade diminui à medida que a renda aumenta e para os quais o ajuste mostrou-se muito bom, com elevado coeficiente de determinação e boa distribuição das dez classes de RFPC pelos três grandes estratos. São eles macarrão com ovos, batata inglesa, mandioca, alface, ameixa, presunto e leite condensado. A Figura 1 mostra as poligonais ajustadas para alguns desses itens. Observa-se que os segmentos da reta passam próximo ou sobre todos os pontos. A maneira como é formada a poligonal em cada caso pode ser consultada na tabela 4 . 
Figura 1 - Poligonais ajustadas para as despesas com batata inglesa, presunto e leite condensado

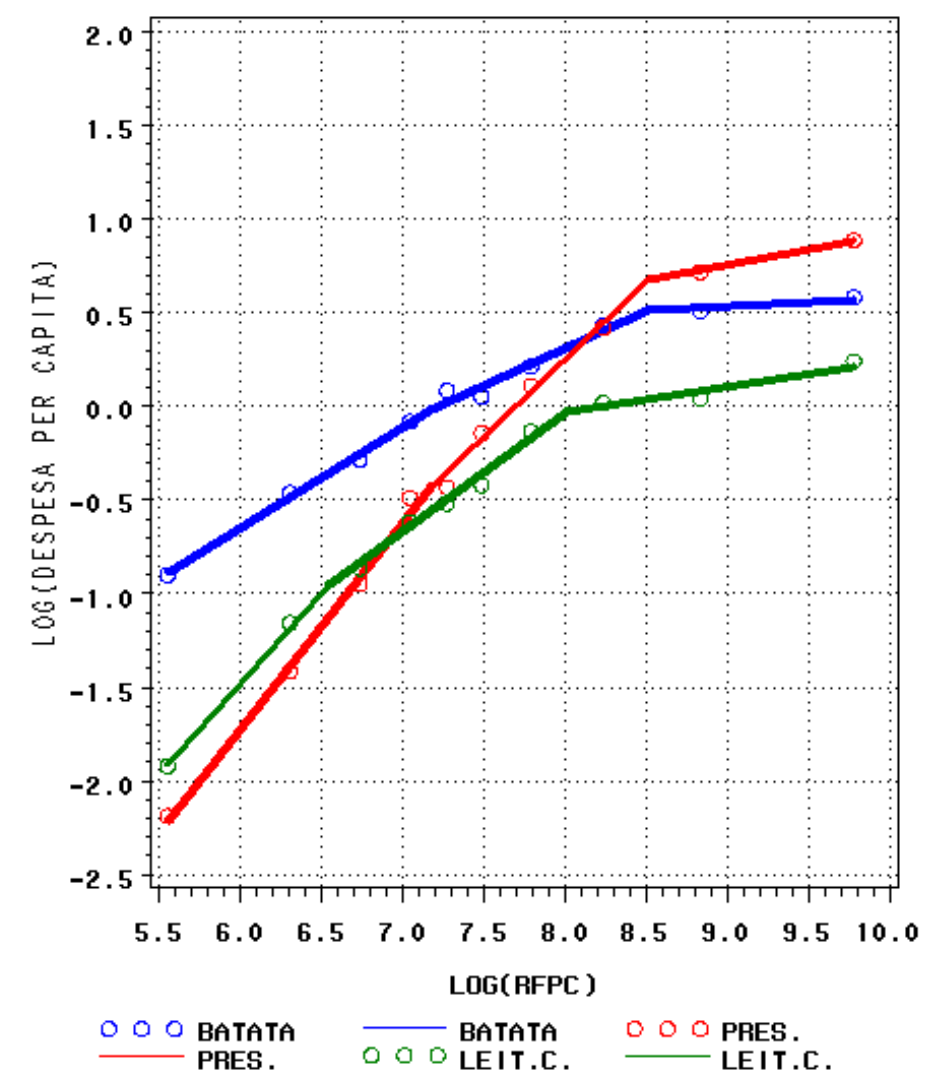

Fonte: elaborada pelos autores com dados da Pesquisa de Orçamentos Familiares 2017-2018.

No caso das despesas com batata inglesa, a elasticidade-renda é de 0,541 no primeiro estrato, que inclui as quatro classes mais pobres (rendimentos mensais de até $\mathrm{R} \$ 1.300$ per capita), mas diminui para 0,392 no estrato intermediário, que inclui as quatro classes seguintes, com rendimentos entre $\mathrm{R} \$ 1.300$ e $\mathrm{R} \$ 5.000$. No estrato mais rico, que inclui as duas últimas classes da RFPC, a demanda torna-se fortemente inelástica $(\varepsilon=0,048)$, mostrando que para essas classes a batata inglesa é um bem de consumo praticamente saciado.

A título de comparação, a Tabela 4 também apresenta as elasticidades-renda médias obtidas por Hoffmann (2007 e 2010) com base nas edições de 2002-2003 e 2008-2009 da POF, calculadas utilizando-se a mesma metodologia adotada neste trabalho. A comparação das três edições da POF mostra um aumento da elasticidade-renda média das despesas com alimentação no domicílio, que passou de 0,381 em 2002-2003 para 0,407 em 2008-2009 e 0,464 em 2017-2018. Esse 
aumento das elasticidades, concomitantemente à redução do gasto médio familiar per capita, comentada na seção anterior, pode estar associado à melhor qualidade (e maior preço) dos produtos adquiridos pelos relativamente ricos. Em contrapartida, a elasticidade-renda das despesas com alimentação fora do domicílio, que havia se elevado de 0,798 para 0,828 entre 2002-2003 e 2008-2009, declinou em 2017-2018 ( $\varepsilon=0,789)$.

É interessante notar como a preocupação em realizar uma alimentação saudável, associada às recomendações dietéticas de nutricionistas e da comunidade médica, influencia o padrão alimentar da população. Entre as décadas de 60 e 80 observou-se tendência à substituição da manteiga pela margarina. Entre a POF 1961-63 e a POF 1987-88 a participação da manteiga no consumo calórico total caiu de $2,2 \%$ para $0,6 \%$ e a da margarina subiu de $0,4 \%$ para 2,5\% nas áreas metropolitanas investigadas nessas pesquisas (MONDINI; MONTEIRO, 1994). Porém, ao longo das décadas de 90 e 2000, uma série de estudos mostrou que o processo de fabricação da margarina leva à formação de gorduras trans, que aumentam o risco de se desenvolver doenças cardiovasculares (OVIEDO, 2010). No Brasil, a partir de 2006 passou a ser obrigatória a declaração do conteúdo de gordura trans nas embalagens dos alimentos. Com isso, a imagem da margarina como alimento saudável ficou prejudicada e o consumo de manteiga voltou a aumentar. Os dados da Tabela 4 ilustram essas tendências, que são observadas com certa defasagem no tempo: o consumo médio de manteiga caiu de 2002-2003 para 2008-2009, mas aumentou em 2017-2018, tendo sua elasticidade-renda aumentado substancialmente de 2008-2009 para 2017-2018, enquanto a da margarina diminuiu.

\subsection{Curvas de concentração das despesas}

A Tabela 5 apresenta a participação da despesa com alimentação na renda familiar, para itens selecionados, conforme os décimos da distribuição da RFPC, com base nos dados da POF 2017-2018. Além disso, na segunda coluna dessa tabela é possível verificar o percentual da renda total apropriado por cada décimo da população. A desigualdade de renda fica patente ao se observar que o décimo mais pobre da população detém $1,17 \%$ da renda total, ao passo que o décimo mais rico se apropria de $42,68 \%$. 
As participações dos gastos com alimentação no domicílio, com farinha de mandioca e com carne de boi de segunda invariavelmente diminuem à medida que a renda aumenta, o que é ilustrativo da Lei de Engel. No décimo mais pobre da população, por exemplo, quase um terço da renda é despendido com alimentação no domicílio, ao passo que no décimo mais rico esse percentual é de apenas 4\%. Os gastos com farinha de mandioca, por sua vez, têm representatividade na renda do décimo mais pobre mais de sessenta vezes maior que na renda no décimo mais rico.

Tabela 5 - Participação (em \%) da despesa com alimentação na renda familiar, para itens selecionados, conforme décimos da distribuição da RFPC, Brasil, 2017-2018

\begin{tabular}{|c|c|c|c|c|c|c|c|}
\hline \multirow[b]{2}{*}{$\begin{array}{c}\text { Décimo } \\
\text { da } \\
\text { RFPC }\end{array}$} & \multirow[b]{2}{*}{$\begin{array}{l}\text { Percentual } \\
\text { da renda }\end{array}$} & \multicolumn{6}{|c|}{ Percentual da renda familiar per capita despendida com } \\
\hline & & $\begin{array}{l}\text { Alimentação } \\
\text { no domicílio }\end{array}$ & $\begin{array}{c}\text { Farinha } \\
\text { de } \\
\text { mandioca }\end{array}$ & $\begin{array}{l}\text { Carne de } \\
\text { boi de } 1^{a}\end{array}$ & $\begin{array}{l}\text { Carne de } \\
\text { boi de 2a }\end{array}$ & $\begin{array}{c}\text { Alimentação } \\
\text { fora do } \\
\text { domicílio }\end{array}$ & $\begin{array}{l}\text { Vinho no } \\
\text { domicílio } \\
\text { e fora }\end{array}$ \\
\hline $1^{\mathrm{o}}$ & 1,17 & 32,6 & 0,61 & 1,03 & 1,54 & 6,27 & 0,02 \\
\hline $2^{\underline{o}}$ & 2,26 & 20,6 & 0,27 & 0,70 & 0,93 & 6,14 & 0,03 \\
\hline $3^{\underline{o}}$ & 3,22 & 16,5 & 0,16 & 0,68 & 0,75 & 5,38 & 0,03 \\
\hline $4^{\mathrm{o}}$ & 4,21 & 13,9 & 0,11 & 0,55 & 0,59 & 5,08 & 0,02 \\
\hline $5^{0}$ & 5,32 & 13,0 & 0,08 & 0,55 & 0,58 & 5,11 & 0,02 \\
\hline $6^{-}$ & 6,61 & 11,1 & 0,06 & 0,65 & 0,49 & 4,49 & 0,03 \\
\hline $7^{0}$ & 8,24 & 10,2 & 0,05 & 0,53 & 0,41 & 4,56 & 0,04 \\
\hline $8^{\circ}$ & 10,70 & 9,16 & 0,03 & 0,59 & 0,37 & 4,29 & 0,04 \\
\hline $9^{\underline{o}}$ & 15,58 & 7,57 & 0,02 & 0,49 & 0,27 & 4,13 & 0,04 \\
\hline $10^{\circ}$ & 42,68 & 4,11 & 0,01 & 0,29 & 0,09 & 3,12 & 0,07 \\
\hline
\end{tabular}

Fonte: elaborada pelos autores com dados da Pesquisa de Orçamentos Familiares 2017-2018.

Na Tabela 6 encontram-se as participações das despesas totais com alimentação dentro e fora do domicílio na renda per capita e as respectivas razões de concentração. Também são considerados gastos com alimentos selecionados. $\mathrm{Na}$ última linha dessa tabela está a renda familiar per capita, cuja razão de concentração equivale ao índice de Gini da respectiva distribuição.

Observa-se que a alimentação fora do domicílio possui maior razão de concentração $(0,434)$ que a alimentação no domicílio $(0,254)$. Ainda assim, ambas são menos concentradas que a renda, cujo Gini é de 0,535 . Embora a alimentação fora do domicílio esteja associada frequentemente ao lazer, ela também é, em muitos casos, uma necessidade básica da população, sendo realizada por 
estudantes em escolas e universidades das redes pública e privada, bem como por trabalhadores de diferentes classes de renda nos refeitórios das empresas ou em estabelecimentos comerciais, onde pode ser adquirida a preços mais acessíveis sob a forma do "prato feito" ou "marmitex".

Nota-se, por outro lado, que as despesas alimentares mais concentradas em favor dos relativamente ricos estão associadas a uma seleção alimentar mais criteriosa quanto à qualidade dos alimentos ingeridos e a seu valor calórico, e, também, ao consumo de alimentos sofisticados. É o caso das despesas com leites e derivados orgânicos, panificados light e diet, bebidas não alcoólicas light e diet e vinho no domicílio e fora. Com relação às despesas com vinho, vê-se, na Tabela 5 , que ele representa um percentual maior da renda $(0,07 \%)$ no décimo mais rico da renda familiar per capita.

\section{Tabela 6 - Razões de Concentração e participação de cada categoria de despesa na renda, Brasil, 2017-2018}

\begin{tabular}{l|r|r}
\hline Categorias de despesa ou renda & $\begin{array}{r}\text { Participação da despesa } \\
\text { na renda per capita }(\%)\end{array}$ & $\begin{array}{r}\text { Razão de } \\
\text { concentração }\end{array}$ \\
\hline Alimentação no domicílio & 8,150 & 0,254 \\
Alimentação fora do domicílio & 3,980 & 0,434 \\
Farinha de mandioca & 0,044 & $-0,175$ \\
Carne de boi de $1^{\underline{a}}$ & 0,451 & 0,383 \\
Carne de boi de $2^{\underline{a}}$ & 0,302 & 0,136 \\
Frutas & 0,425 & 0,373 \\
Leites e derivados & 0,865 & 0,311 \\
Leites e derivados orgânicos & 0,002 & 0,655 \\
Panificados & 0,835 & 0,224 \\
Panificados light e diet & 0,004 & 0,665 \\
Refrigerantes & 0,222 & 0,311 \\
Bebidas não alcoólicas light e diet & 0,007 & 0,731 \\
Vinho no domicílio e fora & 0,048 & 0,709 \\
Renda familiar per capita & 100,000 & 0,535 \\
\hline
\end{tabular}

Fonte: elaborada pelos autores com dados da Pesquisa de Orçamentos Familiares 2017-2018.

A figura 2, a seguir, contém as curvas de concentração para itens selecionados de despesas e a curva de Lorenz da RFPC. Conforme explicado na seção 3.2.2, existe uma relação direta entre as elasticidades-renda, as razões e as curvas de concentração. Para um bem normal, cuja elasticidade é menor do que a unidade, a curva de concentração fica acima (e à esquerda) da curva de Lorenz. Quando a elasticidade é negativa (caso especial da farinha de mandioca), a curva 
fica acima do bissetor do primeiro quadrante. Em se tratando de bens superiores, cuja elasticidade é superior à unidade, a curva tende a ficar abaixo (e à direita) da curva de Lorenz.

Figura 2 - Curva de Lorenz da RFPC e curvas de concentração das despesas com alimentação no domicílio, alimentação fora do domicílio, carne de boi de $1^{a}$, carne de boi de $2^{2}$, farinha de mandioca e vinho, Brasil, 2017-2018

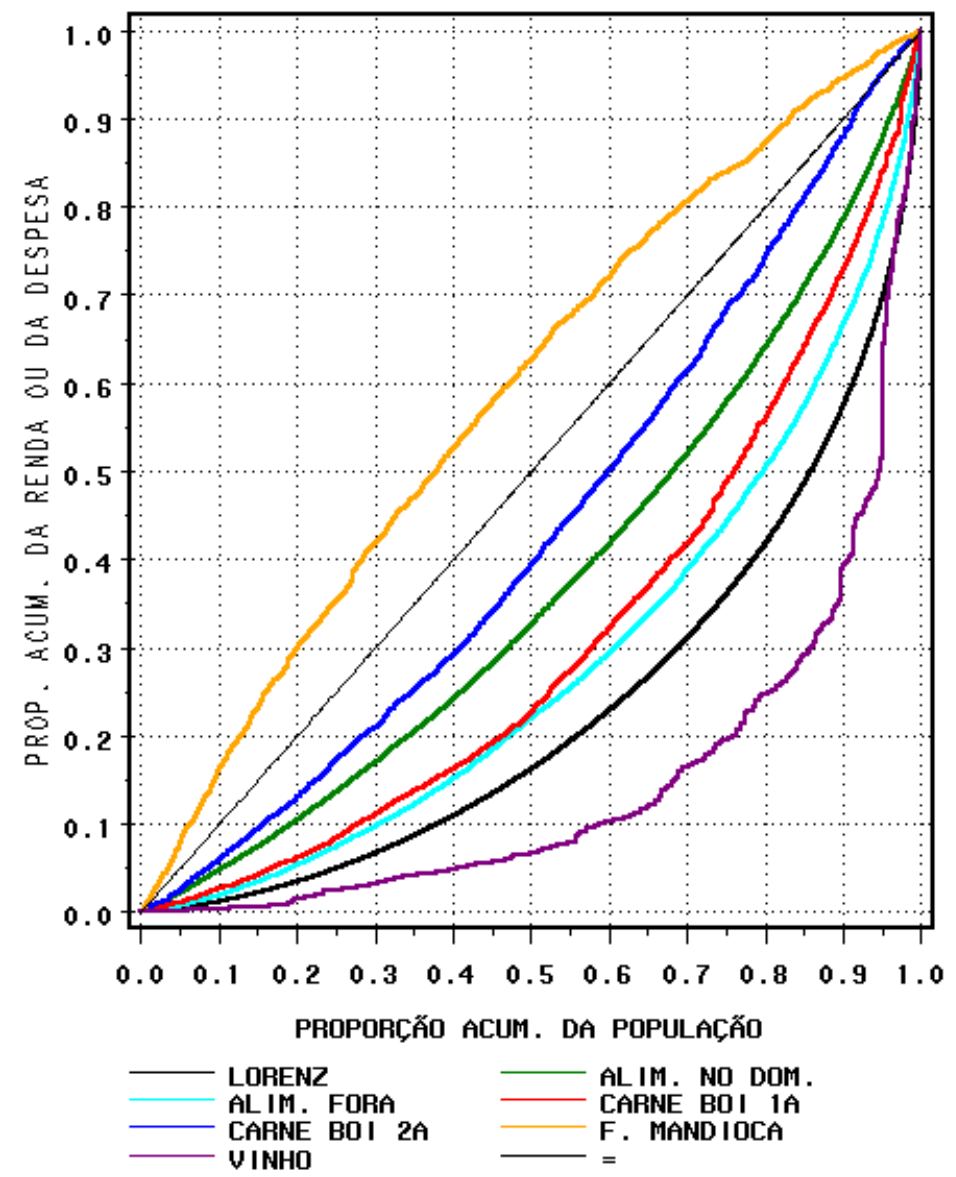

Fonte: elaborada pelos autores com dados da Pesquisa de Orçamentos Familiares 2017-2018.

A despesa com vinho consumido fora do domicílio apresenta a maior elasticidade-renda média de todos os itens listados na tabela 4. Agregando-se essas despesas àquelas relativas ao consumo de vinho dentro do domicílio, obtém-se uma elasticidade-renda média um pouco menor $(1,296)$, porém ainda muito elevada e que alça esse produto à condição de bem de luxo. Essa despesa se mostra mais concentrada do que a renda e, portanto, na Figura 2, sua curva de concentração é a mais externa em relação à bissetriz do quadrante. Além disso, por 
ter a elasticidade dos dois primeiros grandes estratos acima da unidade, a curva de concentração fica externa à curva de Lorenz em grande parte da distribuição.

Nota-se que um produto mais barato, como a carne de boi de segunda, é menos concentrado em favor dos relativamente ricos do que um produto mais caro, como a carne de boi de primeira. Como consequência, sua curva de concentração situa-se mais próxima da bissetriz do quadrante. Consultando a Tabela 4, verifica-se que a elasticidade-renda média da carne de boi de segunda é bastante baixa $(0,253)$, tornando-se negativa no terceiro estrato. Com efeito, a curva de concentração dessa despesa cruza a bissetriz do quadrante um pouco acima do $90^{\circ}$ percentil.

\section{Considerações finais}

As mudanças no padrão de consumo alimentar da população brasileira ao longo das últimas décadas têm resultado na redução do consumo de gêneros tradicionais, como arroz, feijão, batata, pão e açúcar, no aumento da aquisição de produtos industrializados, prontos para consumo ou de fácil preparo, e na expansão dos gastos com alimentação fora de casa.

A análise dos primeiros resultados da POF 2017-2018 mostrou que a crise econômica que atingiu o País a partir de meados de 2014 interrompeu algumas dessas tendências, como a de crescimento do gasto com alimentação fora do domicílio, bem como do gasto no domicílio com carnes, vísceras e pescados. A trajetória declinante dos gastos com açúcar - que vinha sendo substituído por produtos industrializados - foi revertida, tendo esse tipo de dispêndio aumentado em 2017-2018.

As elevadas elasticidades-renda das despesas com produtos orgânicos e light/diet mostram que esses produtos são mais demandados pelos relativamente ricos e possuem potencial de crescimento do consumo no mercado interno. $\mathrm{O}$ gráfico com as curvas de concentração de algumas categorias de despesa permite constatar que aquelas mais concentradas nos relativamente ricos estão associadas a uma dieta mais criteriosa e sofisticada, sendo o vinho um caso emblemático.

Os resultados encontrados neste trabalho são relevantes para a análise do comportamento da demanda dos consumidores por alimentos e na identificação de padrões alimentares na população, podendo auxiliar na formulação de políticas 
públicas nas áreas de alimentação e nutrição, bem como na elaboração de estratégias de mercado por parte da indústria alimentícia.

\section{Referências}

FGV. Balanço e disponibilidade interna de gêneros alimentícios de origem vegetal 1986 a 1990. Rio de Janeiro: Centro de Estudos Agrícolas, Instituto Brasileiro de Economia, Fundação Getúlio Vargas, 1991.

HOFFMANN, R. A Diminuição do consumo de feijão no Brasil. Estudos Econômicos, v. 25, n. 2, p. 189-201, 1995.

HOFFMANN, R. Elasticidades-renda das despesas e do consumo de alimentos no Brasil em 2002-2003. In: SILVEIRA, F. G.; SERVO, L. M. S.; MENEZES, T.; PIOLA, S. G. (Orgs.). Gasto e consumo das famílias brasileiras contemporâneas. Brasília: IPEA, v. 2, p. 463-483, 2007.

HOFFMANN, R. Estimativas das elasticidades-renda de várias categorias de despesa e de consumo, especialmente alimentos, no Brasil, com base na POF de 2008-2009. Revista de Economia Agrícola, v. 57, n. 2, p. 49-62, 2010.

HOFFMANN, R. Comparando a alimentação dentro e fora do domicílio, no Brasil, em 2008-2009. Segurança Alimentar e Nutricional, v. 20, n. 1, p. 1-12, 2013.

IBGE. Pesquisa de orçamentos familiares 2017-2018: primeiros resultados. Instituto Brasileiro de Geografia e Estatística, Coordenação de Trabalho e Rendimento. Rio de Janeiro: IBGE, 2019.

KAKWANI, N. C. Applications of Lorenz curves in economic analysis. Econometrica, v. 45, n. 3, p. 719-727, 1977.

LEAL, D. Crescimento da alimentação fora do domicílio. Segurança Alimentar e Nutricional, v. 17, n. 1, p. 123-132, 2010.

LOUZADA, M. L. C. et al. Ultra-processed foods and the nutritional dietary profile in Brazil. Revista Saúde Pública, v. 49, 2015.

MALTA, D. C. et al. Consumo de bebidas alcoólicas e direção de veículos, balanço da lei seca, Brasil 2007 a 2013. Revista Saúde Pública, v. 48, n. 4, p. 692696, 2014.

MARTINS, A. P. B. et al. Participação crescente de produtos ultraprocessados na dieta brasileira (1987-2009). Revista Saúde Pública, v. 47, n. 4, p. 656-665, 2013. 
MONDINI, L.; MONTEIRO, C. A. Mudanças no padrão de alimentação da população urbana brasileira (1962-1988). Revista Saúde Pública, v. 28, n. 6, p. 433-439, 1994.

OLIVEIRA, F. C. R.; HOFFMANN, R. Consumo de alimentos orgânicos e de produtos light ou diet no Brasil: fatores condicionantes e elasticidades-renda. Segurança Alimentar e Nutricional, v. 22, n. 1, p. 541-557, nov. 2015.

OVIEDO, K. M. M. Análise comparativa das experiências de regulação de gorduras trans em alimentos processados no Brasil, Canadá, Dinamarca e Estados Unidos. Rio de Janeiro, 2010, 141 p. Dissertação de Mestrado, Pontifícia Universidade Católica do Rio de Janeiro.

SOUZA, A. M. et al. Alimentos mais consumidos no Brasil: Inquérito Nacional de Alimentação 2008-2009. Revista Saúde Pública, v. 47, supl. 1, p. 190-199, 2013.

SOUZA, M. J. P.; OLIVEIRA, P. R.; BURNQUIST, H. L. Lar "Doce” Lar: uma análise do consumo de açúcar e de produtos relacionados no Brasil. Revista Economia e Sociologia Rural, v. 51, n. 4, p. 785-796, 2013.

VIEIRA, R. C. M. T. (Coord.) Avaliação global do setor agrícola: grãos no Brasil. Brasília: IPEA (Estudos de Política Agrícola. Documentos de Trabalho, 25), 1994. 